UNDERGRADUATE RESEARCH IN NATURAL AND CLINICAL SCIENCE AND TECHNOLOGY (URNCST) JOURNAL Read more URNCST Journal articles and submit your own today at: https://www.urncst.com

\title{
Wearable Health Technology for the Diagnosis and Management of Atrial Fibrillation: A Systematic Review
}

\author{
Ervis Musa, BHSc Student [1]*, Adam Z. Levitan, BSc Student [2], Gavin Hughes, BHSc \\ Student [1] \\ [1] Faculty of Health Sciences, Queen's University, Kingston, ON, Canada, K7L 3L4 \\ [2] Department of Biology, Queen's University, Kingston, ON, Canada, K7L 3N6
}

*Corresponding Author: musa.ervis@queensu.ca

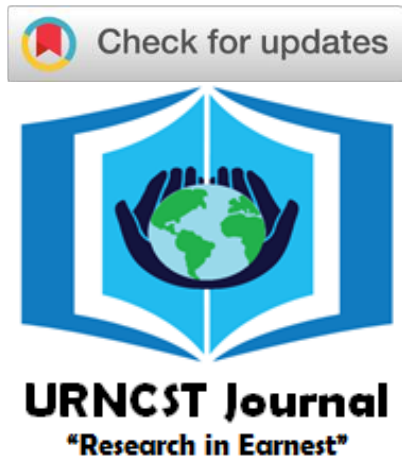

\begin{abstract}
Introduction: Atrial Fibrillation (AF), the most commonly sustained arrhythmia, affects approximately 200,000 Canadians and costs an annual $\$ 815$ million to the Ontario provincial healthcare system. The current model for chronic AF management (favouring infrequent hospital visits) in combination with the challenge of detecting cardiac arrythmias provides opportunity for wearable devices to improve quality of care. Physicians must be aware of available wearable devices, their accuracy, validity, and potential to improve patient care.

Methods: PubMed and Google Scholar databases were searched for primary studies involving AF and wearable devices published from database inception to 2020. Due to the heterogeneity of the findings, quantitative synthesis of the information could not be conducted. A narrative synthesis was performed for the obtained results, including a discussion of apparent trends and common study outcome measures: sensitivity, specificity, positive-, and negative-predictive-values. The narrative included comparisons to similar reviews and a discussion on both the current and future research directions.

Results: The systematic search produced 214 studies, of which, 7 met the pre-determined eligibility criteria. The studies were published between 2018-2020 in 5 countries. Each eligible study was described and summarized; devices investigated include the Apple Watch with Kardia Band (Atrial fibrillation-sensing watch; AFSW), Huawei wearable devices (Honor 4 wristband, Honor Watch or Watch GT), CardioTracker (CART) + a pulse oximeter, and the RITMA system.

Discussion: This systematic review comprehensively examined wearable devices used to deliver care for patients with AF. It was found that currently available wearable technologies for AF detection and management varied greatly in their accuracy, application settings, and accessibility. With technological advancements and further exploration into AF devices' usability, widespread implementation of wearable technology in AF care is plausible. Successful application of these technologies can improve AF care and contribute to a significant reduction in AF-related healthcare costs.

Conclusion: There are many devices available for AF care that show promise for certain applications. Additionally, there remains a demand for large-scale, high-quality research in this field to investigate the advantages and shortcomings of various devices that have shown promise in preliminary research. Future research should focus on randomized controlled trials to generate conclusive findings for wearable technologies in AF.
\end{abstract}

Keywords: atrial fibrillation; wearable devices; electrocardiogram; remote monitoring

\section{Introduction}

Atrial fibrillation (AF), the most commonly sustained heart arrhythmia, causes symptoms of heart palpitations, fatigue and chest discomfort for approximately 200,000 Canadians $[1,2]$. Costing the Ontario provincial healthcare system $\$ 815$ million annually, $\mathrm{AF}$ is frequently complicated by comorbid conditions such as chronic kidney disease, obstructive sleep apnea, and pulmonary disease [3,4]. In general, AF presentation is unpredictable and sporadic, where some patients may be asymptomatic, posing a diagnostic challenge [4]. As such, treatment and management of AF can be difficult for both patients and providers [4]. Delayed diagnoses and subsequent disease progression may result in more severe cardiovascular

Musa et al. | URNCST Journal (2021): Volume 5, Issue 4

DOI Link: https://doi.org/10.26685/urncst.230 abnormalities, such as stroke and heart failure [5,6].

Physician and healthcare system efforts are often targeted towards using technology for preventing complications and improving quality of life [5]. In the current healthcare system, AF follow-up care is commonly delivered at a fixed schedule, with infrequent clinician visits providing limited insight into the chronicity of the patient's disease condition [4].

Wearable technology - defined as externally applied electronic devices, and any accompanying resources, that measure a physiological signal - may offer a potential opportunity to improve arrhythmia detection, advise clinical responses and enhance quality of life for patients with AF. Preliminary studies have shown that early detection through 


\section{UNDERGRADUATE RESEARCH IN NATURAL AND CLINICAL SCIENCE AND TECHNOLOGY (URNCST) JOURNAL}

Read more URNCST Journal articles and submit your own today at: https://www.urncst.com

wearable technologies results in more prompt clinical responses and prevents disease exacerbations, resulting in improved care and patient health [7]. Additional studies have demonstrated that remote monitoring by wearable devices has reduced the occurrence of strokes, significantly improved clinical efficiency and has also improved patient retention and adherence to treatment follow-up schedules [8].

Despite the significant potential that wearable technologies offer to AF patients and providers, noninvasive commercially available wearable devices are not without limitations. Healthcare professionals and consumers need to be aware of the accuracy, validity and availability of the devices and the medical data afforded by these technologies. A recent survey found that $62 \%$ of participating physicians desired further recommendations on the use of wearable devices from trusted sources within the scientific community [9].

This systematic review explores wearable devices that can be used to deliver care for patients with AF and identifies their strengths and weaknesses. Additionally, this review used the obtained findings to outline the implications of and barriers to wide-scale implementation of remote monitoring/wearable devices while providing directions for future research to provide the highest quality of care for those with AF.

\section{Methods}

\section{Research Question}

This review, and the reporting, followed the Preferred Reporting Items for Systematic Reviews and Meta-Analyses guidelines [10]. The primary question guiding our review was: What wearable devices are available and used to deliver care for patients with AF?

The secondary research objective was to determine the degree of accuracy, validity, and reliability of the information provided by wearable devices, in relation to the ability of the devices to manage AF, detect new cases of AF, and to improve quality of care.

\section{Search Strategy}

PubMed and Google Scholar databases were searched to identify relevant English-language articles published from inception of databases until August 2020. The search terms used were: "Atrial Fibrillation", "AFib", and "AF" in combination with "digital health", "wearable electronic devices", and "eHealth". Primary studies were not restricted by study design (e.g. cohort, case-control, etc.), but systematic reviews and other secondary literature sources were excluded. Both peer-reviewed and grey literature were included.

\section{$\underline{\text { Study Selection }}$}

Eligibility criteria were as follows: Studies were required to be primary research focused on the management and/or diagnosis of AF using interventions that included wearable technology and published in the English language.
Screening of titles/abstracts followed by full-text screening was conducted independently by each author and in duplicate. All authors resolved discrepancies in unison, or via consultation with an individual knowledgeable in research methodology, cardiology and/or digital health.

\section{Synthesis of Information}

Due to the heterogeneity of the studies that met eligibility criteria and the subsequent reporting and outcome measures, we were unable to perform a quantitative synthesis of the results. For this reason, we performed a narrative analysis of the results which included documenting the study design, description of intervention and methods, results of the individual studies and conducting a thematic analysis to synthesize the main information.

\section{Quality Assessment}

We planned to assess study quality using the risk of bias tools recommended by the Cochrane group [11]. However, due to the heterogeneity of study design - which included derivation, proof of concept studies and preliminary studies - a meaningful quantitative assessment and synthesis of study quality was not possible.

\section{Results}

Overview

The database searches produced 214 studies, from these, 70 were excluded based on title and abstract review. 130 fulltext articles were assessed and 7 met the eligibility criteria (Figure $1 \&$ Table 1). The included studies were published in the year 2018 or later, with a cohort study identified as the most common (5/7) study design. For these studies, we found that the average size of the cohort of interest was approximately 455 participants (range: 2 - 2,161; $\mathrm{SD}=840$ ).

\section{Wearable technology overview}

All of the devices in the 7 included studies used photoplethysmography (PPG) technology, which uses diodes to emit and detect light to discontinuously and passively detect changes in blood volume in real-time [12-18]. Two studies investigated the Apple Watch + Kardia Band (AFSW) $[13,14]$. The following technologies were investigated by one study each: Huawei wearable devices (Honor 4 wristband, Honor Watch or Watch GT) [15], CART + a pulse oximeter [16], the RITMA system [17], and the iRhythm Zio patch [18]. Many devices were compared with the current gold standard 12-lead electrocardiogram (ECG), but none were able to effectively detect AF to the same degree of accuracy. Many showed promising results in smaller sample sizes (Table 1). A lack of consensus evident among study results and conclusions illustrates the need for large-scale, high-quality research assessing wearable devices such as the popular Huawei health tracking devices, AFSW and CART. This will allow for the accurate depiction of the strengths and weaknesses of each wearable device in Comparison to the gold standard, in-person 12-lead ECG. 
UNDERGRADUATE RESEARCH IN NATURAL AND CLINICAL SCIENCE AND TECHNOLOGY (URNCST) JOURNAL Read more URNCST Journal articles and submit your own today at: https://www.urncst.com

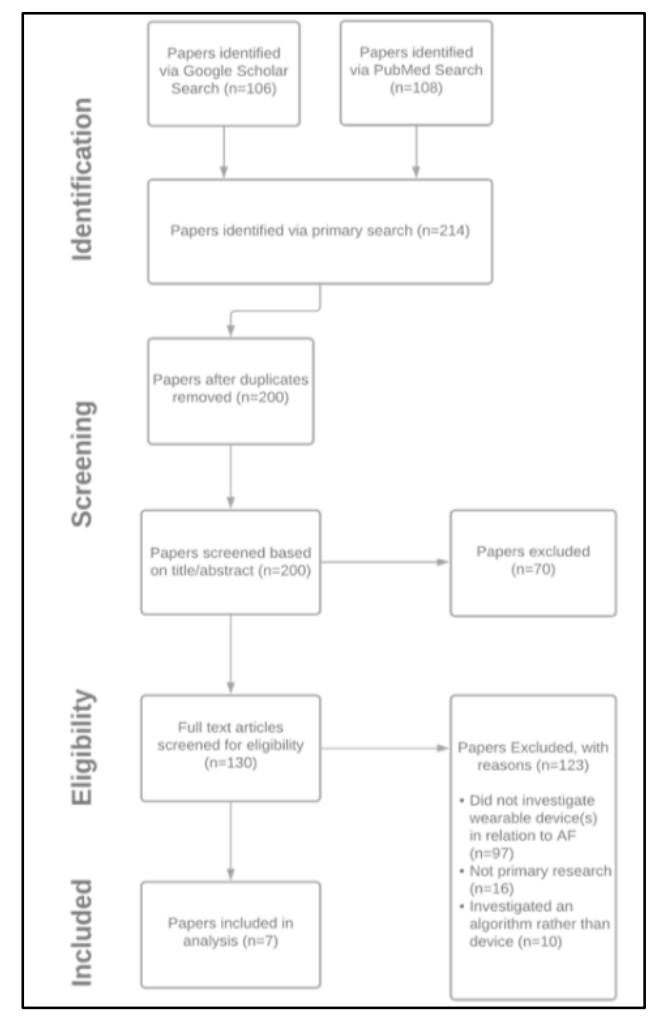

Figure 1. Flow diagram of research papers from identification to inclusion.

\section{Description of included studies}

The study conducted by Bumgarner et al. demonstrated that the Apple Watch + Kardia Band (ASFW) effectively differentiated between $\mathrm{AF}$ and sinus rhythm (SR) in AF patients [13]. However, due to the small sample size $(n=85)$ and severity of AF prompting electrical cardioversion, the results may be less pronounced in a more general population with less severe AF. Additionally, this study found that $33.7 \%$ of recordings taken were classified as "missing/uninterpretable", indicative of the device's ability to filter noise from signal, and therefore serve as an effective and accurate tool in AF care.

The study conducted by Guo et al. included a large sample size of participants without prior AF diagnosis $(n=187,912)$ who wore the Honor 4 wristband, Honor Watch or the Huawei Watch GT to monitor heart rhythm [15]. Combined, the devices were $87 \%$ accurate in detecting AF; however, compliance was low - 38\% of individuals with "suspected AF" did not continue with the follow-up ("suspected AF" could not be confirmed or falsified).

The study conducted by Kwon et al. examined the wearable 'CART' technology in a sample size of 100 participants [16]. This ring-type wearable device showed great promise for effective $\mathrm{AF}$ detection with extremely high accuracy, sensitivity, and specificity. However, 'CART' must be paired with a pulse oximeter and thus may negatively affect $\mathrm{AF}$ patient compliance/uptake.

In a study funded by Apple, Perez et al. demonstrated that irregular pulse notifications from the Apple Watch were confirmed by subsequent ECG patch readings $34 \%$ of the time [12]. The study included the first large-scale AF detection assessment to date $(n=419,297)$. While the study did investigate the effectiveness of the device in a large sample, the study design was flawed. The gap of time between the initial notification and subsequent ECG patch recording limits the validity of the comparison as there was a significant amount of time between the recordings from each comparator. Furthermore, the eligibility criteria for the study did not designate which series of Apple Watch was required, meaning the results were provided by a combination of all 4 series that were available at the time of the study. This provides a source of error as the accuracy of information from each series differs (due to hardware and software upgrades in later models), essentially meaning the study was conducted on 4 devices mixed within a single sample with unknown proportions.

The study conducted by Reverberi et al. on a small sample $(n=95)$ observed that the RITMA system demonstrated high sensitivity and specificity in its ability to differentiate between AF and SR compared with 12-lead ECG [17]. This system consists of an affordable Bluetooth heart rate monitor attached by a chest strap. The RITMA technology has long-term monitoring functionality, allowing it to detect patients at risk for silent AF. However, the study was conducted on a study population where more than half of participants (54.4\%) had AF, meaning system accuracy may vary when applied to general screening settings.

The mHealth Screening to Prevent Strokes (mSToPS) trial conducted by Steinhubl et al. examined the role of selfapplied wearable ECGs in AF detection and their subsequent clinical impact [18]. While the study did not compare the accuracy of any wearable device to a gold standard, they did find that active remote monitoring led to more frequent diagnosis of $\mathrm{AF}$ and initiation of anticoagulation therapy.

Wasserlauf et al. used the AFSW to detect episodes of $\mathrm{AF} \geq 1$ hour in duration with high sensitivity, but low positive predictive value (PPV) [14]. They were required to examine only episodes of $\mathrm{AF} \geq 1$ hour because there was a high false-positive rate for shorter episodes, a recurring limitation. The study also found the AFSW to be very effective in detecting AF episode duration, as well as a higher rate of AF diagnosis in the active RM group relative to the control. Interestingly, of the 109 individuals diagnosed with $\mathrm{AF}$ in the active RM group, 65 of them $(60 \%)$ were first found to have AF by ECG patch during the study, while 44 received a diagnosis before or after monitoring was completed. 
UNDERGRADUATE RESEARCH IN NATURAL AND CLINICAL SCIENCE AND TECHNOLOGY (URNCST) JOURNAL Read more URNCST Journal articles and submit your own today at: https://www.urncst.com

Table 1. Individual analysis of the seven articles that have met eligibility criteria.

\begin{tabular}{|c|c|c|c|}
\hline Reference & Study Design & Intervention Description & Results Overview[*] \\
\hline $\begin{array}{l}\text { Bumgarner, } \\
\text { 2018, USA } \\
{[13]}\end{array}$ & $\begin{array}{l}\text { Cohort study } \\
(\mathrm{n}=85)\end{array}$ & $\begin{array}{l}\text { Participants underwent cardioversion. ECG } \\
\text { recordings followed by AFSW recordings were } \\
\text { taken before and after cardioversion. }\end{array}$ & $\begin{array}{l}\text { The device effectively differentiated between } \\
\text { NSR and AF (sensitivity }=93 \% \text {, specificity }=84 \% \text {, } \\
\text { K coefficient }=0.77) \text {. PPV \& NPV not reported. }\end{array}$ \\
\hline $\begin{array}{l}\text { Guo, 2019, } \\
\text { China [15] }\end{array}$ & $\begin{array}{l}\text { Cohort study } \\
(\mathrm{n}=187,912)\end{array}$ & $\begin{array}{l}\text { Participants monitored heart rhythm using } \\
\text { either the Honor } 4 \text { wristband, Honor Watch or } \\
\text { the Huawei Watch GT. Those identified as } \\
\text { "possible AF" were directed to a hospital for } \\
\text { further care and validation or falsification. }\end{array}$ & $\begin{array}{l}\text { Of the participants who were identified as } \\
\text { "possible AF" and effectively followed up } \\
\text { (n=262), 87.0\% were confirmed as having AF } \\
\text { (PPV=91.6\%, 95\% confidence interval (CI) } \\
91.5 \%-91.8 \%) .\end{array}$ \\
\hline $\begin{array}{l}\text { Kwon, 2020, } \\
\text { South Korea } \\
{[16]}\end{array}$ & $\begin{array}{l}\text { Cohort study } \\
(\mathrm{n}=100)\end{array}$ & $\begin{array}{l}\text { Participants with persistent AF. Used the ring- } \\
\text { type wearable 'CART' + pulse oximeter. The } \\
\text { accuracy of AF detection was validated by } \\
\text { single-lead ECG. }\end{array}$ & $\begin{array}{l}\text { The device was effective for AF detection } \\
\text { (accuracy=96.9\%, sensitivity }=99.0 \% \text {, } \\
\text { specificity }=94.3 \%, \text { PPV=95.6\%, } \\
\text { NPV=98.7\%). }\end{array}$ \\
\hline 19 , & $\begin{array}{l}\text { Prospective } \\
\text { study } \\
(\mathrm{n}=419,297)\end{array}$ & $\begin{array}{l}\text { Participants with an Apple Watch and without } \\
\text { self-reported AF, were notified when the device } \\
\text { detected irregular pulse, and were then } \\
\text { evaluated by a physician via telemedicine. } \\
\text { Those with non-urgent symptoms were mailed } \\
\text { an ePatch to wear for up to } 7 \text { days to confirm or } \\
\text { falsify suspected AF. }\end{array}$ & $\begin{array}{l}\text { Of those notified of irregular pulse }(\mathrm{n}=2,161) \text {, } \\
450 \text { individuals returned ECG patches. AF } \\
\text { was present in } 34 \% \text { of returned ECGs }(97.5 \\
\text { CI: } 29-39, \text { PPV=0.84). }\end{array}$ \\
\hline $\begin{array}{l}\text { Reverberi, } \\
\text { 2019, Italy } \\
{[17]}\end{array}$ & $\begin{array}{l}\text { Cohort study } \\
(\mathrm{n}=95)\end{array}$ & $\begin{array}{l}\text { Patients underwent cardioversion. 12-lead ECG } \\
\text { recordings immediately followed by the } \\
\text { RITMA system (chest strap monitor + RITMA } \\
\text { app) recordings were taken before and after } \\
\text { cardioversion. }\end{array}$ & $\begin{array}{l}\text { The RITMA system effectively detected } \\
\text { "probable AF arrhythmia" effectively } \\
\text { (sensitivity=97.0\%, specificity=95.2\%, kappa } \\
\text { coefficient=92.6\%). }\end{array}$ \\
\hline $\begin{array}{l}\text { Steinhubl, } \\
2018, \text { USA } \\
{[18]}\end{array}$ & $\begin{array}{l}\text { Randomized } \\
\text { controlled trial } \\
(\mathrm{n}=2,659)\end{array}$ & $\begin{array}{l}\text { Individuals were assigned to an immediate- or } \\
\text { delayed-monitoring cohort and provided an } \\
\text { iRhythm Zio patch to record ECGs for two 4- } \\
\text { week periods, each } 3 \text { months apart. }\end{array}$ & $\begin{array}{l}\text { The rate of newly diagnosed AF was higher in } \\
\text { the immediate monitoring group (3.9\%) than } \\
\text { the delayed group }(0.9 \%) \text { (absolute } \\
\text { difference=3.0\%, 95\% confidence interval } \\
\text { (CI) } 3.0 \%-6.1 \%) \text {. Monitored individuals had } \\
\text { higher rates of AF diagnosis and initiation of } \\
\text { anticoagulant therapy. }\end{array}$ \\
\hline $\begin{array}{l}\text { Wasserlauf, } \\
2019, \text { USA } \\
{[14]}\end{array}$ & $\begin{array}{l}\text { Cohort study } \\
(\mathrm{n}=24)\end{array}$ & $\begin{array}{l}\text { Patients with paroxysmal AF. Heart rhythm } \\
\text { recorded by AFSW and compared with } \\
\text { simultaneous implantable cardiac monitor } \\
\text { recordings. }\end{array}$ & $\begin{array}{l}\text { The device reported no false positives among } \\
\text { those who had AF } \geq 1 \text { hour but showed a low } \\
\text { PPV for AF episode detection } \\
\text { (sensitivity=97.5\%, PPV=39.9\%). NPV and } \\
\text { specificity not reported for overall AF episode } \\
\text { detection. }\end{array}$ \\
\hline
\end{tabular}

* - NSR: normal sinus rhythm; PPV: positive predictive value; NPV: negative predictive value; AFSW: Apple Watch \& Kardia Band

\section{Discussion}

This study investigated the potential clinical applications of wearable device technology concerning AF. This systematic review aimed to review and summarize the current state and direction of the field by analysing studies on the accuracy and validity of the information provided by wearable technology for AF detection and management. The 7 studies included in this study demonstrate the variability in device accuracy and application. This variability illustrates the need for large-scale, high quality research into these devices to robustly identify their strengths and weaknesses. In addition, this review highlights the need for further research to inform the technological development and uptake of wearable devices.

A recent review examined use of mobile health (mHealth) devices in AF and provided an overview of available technologies, specific characteristics, and accuracy of mHealth for AF [19]. Similar to the current review, Giebel \& Gissel (2019) also analysed the Apple watch in conjunction with KardiaBand [19]. This study identified that 
UNDERGRADUATE RESEARCH IN NATURAL AND CLINICAL SCIENCE AND TECHNOLOGY (URNCST) JOURNAL Read more URNCST Journal articles and submit your own today at: https://www.urncst.com

combining PPG and ECG in a wrist-worn-wearable is the most effective way to guarantee AF detection, which unfortunately was an analysis our qualitative synthesis was incapable of reproducing. However, their review was subject to alternative findings as it was not limited to wearable technologies and included a broad range of digital and mobile health technologies. In addition, the review by Giebel \& Gissel (2019) narrowly focussed on the accuracy of these devices and lacked exploration of other aspects of the technologies, and excluded articles that did not include information about the accuracy of devices while this review did not [19].

Another recent review overviewed wearable technology in patients with heart failure [20]. Similarly to the present review, this paper outlined the roles and capabilities of wearable devices in managing several aspects of AF, such as lowering blood pressure, symptom monitoring and activity monitoring. Common findings included the current uncertainty yet promising future of the Apple Watch and its activity management accuracy for individuals with AF. In conjunction, the information suggests there may be common device characteristics and themes within wearable technologies across disease states, especially those of cardiovascular origin [20].

Although a quantitative synthesis could not be performed, it was found that studies that devices which did not include supplementary devices (e.g., chest-strap HR monitor, pulse oximeter, Kardia Band) in their AF detection apparatus appeared to demonstrate lower precision compared with those that did. This finding provides a potential limitation to mass screening using devices most typically owned in the general population (e.g., Huawei Watch GT, Apple Watch) that do not contain supplementary devices, and are more commonly purchased by consumers.

Widespread implementation of wearable technology in $\mathrm{AF}$ detection and management has the potential to enhance the quality of AF care by improving clinical efficiency (e.g. further insight into disease progression, increased compliance with anticoagulation therapy) and more timely $\mathrm{AF}$ detection [21]. Improvements may also be observed indirectly through the economic savings associated with improved disease management which would decrease the need for in-person assessments, as well as the number of emergency department visits and hospitalizations. Management of AF with wearable devices may also provide an opportunity to enhance patient-centred health care. The devices can allow patients to become more involved in their health care, which may subsequently improve patient satisfaction, among other outcomes.

However, several points need to be addressed prior to the large-scale adoption of wearable devices for the detection and management of AF. Education should be provided to healthcare providers to improve their ability to optimally recommend/prescribe wearable technologies. Healthcare providers should also be encouraged to participate in the development of technologies to help design user-friendly technologies that meet the needs of patients, providers and the health care system. Patients should be offered training sessions when recommended/prescribed technologies, or when they purchase technologies for medical purposes, and ongoing technical support should also be available to help navigate technical issues. Pricing of wearable technology also provides a point of interest as a balance must be maintained between consumer ability and willingness to pay and the extent of government funding to make the transition feasible. Finally, to ensure large-scale adoption is truly effective, individual technologies must be verified as equivalent in capability to medical-grade equipment/technology.

The present review has several strengths, which include the systematic search directed by the research question, which rigorously identified evidence. Through the use of multiple screeners during the article selection process, the potential of single reviewer bias was reduced. Furthermore, broad eligibility criteria allowed for the inclusion of all types of study designs to allow for the identification of various types of wearable technologies for AF, increasing the generalizability of the findings. However, there are limitations of this review that must be acknowledged. We identified a limited number of studies that met the eligibility criteria, which limits the generalizability of the findings. This review was also limited to the English language, introducing potential language bias. Lastly, given the heterogeneity of the methods, we were unable to perform a meta-analysis.

\section{Conclusions}

While none of the investigated devices were as accurate as the current gold standard, the continual advancement of healthcare technology and patient autonomy makes widespread usage of wearable technology in AF detection and management seemingly inevitable. Wearable technologies have the potential to improve diagnosis and treatment of AF, improve AF quality of care, and reduce the significant cost burden of AF on the health care system. For the field to continue on its trajectory, future research should be directed towards conducting rigorous randomized controlled trials to clearly determine the strengths and weaknesses of wearable technologies, address these weaknesses and devise strategic plans for widespread implementation of wearable technologies for AF patient care.

\section{List of Abbreviations Used}

AF: atrial fibrillation

AFSW: atrial fibrillation sensing-watch

CART: cardiotracker

ECG: electrocardiogram

PPG: photoplethysmography

PPV: positive predictive value

RM: remote monitoring

SR: sinus rhythm 
UNDERGRADUATE RESEARCH IN NATURAL AND CLINICAL SCIENCE AND TECHNOLOGY (URNCST) JOURNAL Read more URNCST Journal articles and submit your own today at: https://www.urncst.com

\section{Conflicts of Interest}

The authors have disclosed no relationships relevant to the contents of this paper.

\section{Ethics Approval and/or Participant Consent}

The authors did not require ethical approval or participant consent for this paper.

\section{Authors' Contributions}

EM: made substantial contributions to the analysis and interpretation of data, drafted the manuscript, and gave final approval of the version to be published.

AL: made substantial contributions to the analysis and interpretation of data, drafted the manuscript, and gave final approval of the version to be published.

GH: made substantial contributions to the analysis and interpretation of data, drafted the manuscript, and gave final approval of the version to be published.

\section{Acknowledgements}

Sera Whitelaw made substantial contributions to the collection of data and revised the manuscript critically.

\section{Funding}

This study was not funded.

\section{References}

[1] Ryder KM, Benjamin EJ. Epidemiology and significance of atrial fibrillation. Am J Cardiol. 1999;84(9A):131R-138R. https://doi.org/10.1016/s00029149(99)00713-4

[2] Atrial fibrillation. Heart and Stroke Foundation of Canada. Availiable from: https://www.heartandstroke .ca/heart-disease/conditions/atrial-fibrillation.

[3] O'Reilly DJ, Hopkins RB, Healey JS, et al. The burden of atrial fibrillation on the hospital sector in Canada. Can J Cardiol. 2013;29(2):229-235. https://doi.org/10.1016/ j.cjca.2012.03.023

[4] Mashat AA, Subki AH, Bakhaider MA, et al. Atrial fibrillation: risk factors and comorbidities in a tertiary center in Jeddah, Saudi Arabia. Int J Gen Med. 2019;12:71-77. https://doi.org/10.2147/IJGM.S188524

[5] Turakhia MP, Kaiser DW. Transforming the care of atrial fibrillation with mobile health. J Interv Card Electrophysiol. 2016;47(1):45-50. https://doi.org/10 $.1007 / \mathrm{s} 10840-016-0136-3$

[6] Brunetti ND, De Gennaro L, Pellegrino PL, Dellegrottaglie G, Antonelli G, Di Biase M. Atrial fibrillation with symptoms other than palpitations: incremental diagnostic sensitivity with at-home telecardiology assessment for emergency medical service. Eur J Prev Cardiol. 2012;19(3):306-313. https://doi.org/ $\underline{10.1177 / 1741826711406060}$

[7] Ricci RP. Disease management: atrial fibrillation and home monitoring. Europace. 2013;15 Suppl 1:i35-i39. https://doi.org/10.1093/europace/eut114

Musa et al. | URNCST Journal (2021): Volume 5, Issue 4 DOI Link: https://doi.org/10.26685/urncst.230
[8] Varma N, Ricci RP. Impact of Remote Monitoring on Clinical Outcomes. J Cardiovasc Electrophysiol. 2015;26 (12):1388-1395. https://doi.org/10.1111/jce.12829

[9] Manninger M, Kosiuk J, Zweiker D, et al. Role of wearable rhythm recordings in clinical decision makingThe wEHRAbles project. Clin Cardiol. 2020;43(9): 1032-1039. https://doi.org/10.1002/clc.23404

[10] Moher D, Liberati A, Tetzlaff J, Altman DG; PRISMA Group. Preferred reporting items for systematic reviews and meta-analyses: the PRISMA statement. PLoS Med. 2009;6(7):e1000097. https://doi.org/10.1371/journal .pmed.1000097

[11] Higgins JP, Thomas J, Chandler J, Cumpston M, Li T, Page MJ, Welch VA, editors. Cochrane handbook for systematic reviews of interventions. John Wiley \& Sons; 2019 Sep 23

[12] Perez MV, Mahaffey KW, Hedlin H, et al. Large-Scale Assessment of a Smartwatch to Identify Atrial Fibrillation. N Engl J Med. 2019;381(20):1909-1917. https://doi.org/10.1056/NEJMoa1901183

[13] Bumgarner JM, Lambert CT, Hussein AA, et al. Smartwatch Algorithm for Automated Detection of Atrial Fibrillation. J Am Coll Cardiol. 2018;71(21):2381-2388. https://doi.org/10.1016/j.jacc.2018.03.003

[14] Wasserlauf J, You C, Patel R, Valys A, Albert D, Passman R. Smartwatch Performance for the Detection and Quantification of Atrial Fibrillation. Circ Arrhythm Electrophysiol. 2019;12(6):e006834. https://doi.org/10 1161/CIRCEP.118.006834

[15] Guo Y, Wang H, Zhang H, et al. Mobile Photoplethysmographic Technology to Detect Atrial Fibrillation. J Am Coll Cardiol. 2019;74(19):23652375. https://doi.org/10.1016/j.jacc.2019.08.019

[16] Kwon S, Hong J, Choi EK, et al. Detection of Atrial Fibrillation Using a Ring-Type Wearable Device (CardioTracker) and Deep Learning Analysis of Photoplethysmography Signals: Prospective Observational Proof-of-Concept Study. J Med Internet Res. 2020;22(5):e16443. https://doi.org/10.2196/16443

[17] Reverberi C, Rabia G, Rosa FD, Bosi D, Botti A, Benatti G. The RITMIA ${ }^{\text {TM }}$ Smartphone App for Automated Detection of Atrial Fibrillation: Accuracy in Consecutive Patients Undergoing Elective Electrical Cardioversion. BioMed Research International. 2019;2019:1-6. https://doi.org/10.1155/2019/4861951.

[18] Steinhubl SR, Waalen J, Edwards AM, et al. Effect of a Home-Based Wearable Continuous ECG Monitoring Patch on Detection of Undiagnosed Atrial Fibrillation: The mSToPS Randomized Clinical Trial. JAMA. 2018;320(2):146-155. https://doi.org/10.1001/jama.2018 .8102

[19] Giebel GD, Gissel C. Accuracy of mHealth Devices for Atrial Fibrillation Screening: Systematic Review. JMIR Mhealth Uhealth. 2019;7(6):e13641. https://doi.org/ $\underline{10.2196 / 13641}$ 
UNDERGRADUATE RESEARCH IN NATURAL AND CLINICAL SCIENCE AND TECHNOLOGY (URNCST) JOURNAL Read more URNCST Journal articles and submit your own today at: https://www.urncst.com

[20] Singhal A, Cowie MR. The Role of Wearables in Heart Failure. Curr Heart Fail Rep. 2020;17(4):125-132. https://doi.org/10.1007/s11897-020-00467-X
[21] Orchard J, Neubeck L, Freedman B, et al. eHealth Tools to Provide Structured Assistance for Atrial FibrillationScreening, Management, and GuidelineRecommended Therapy in Metropolitan General Practice: The AF - SMART Study. J Am Heart Assoc. 2019;8(1):e010959. https://doi.org/10.1161/JAHA.118.010959

\section{Article Information}

Managing Editor: Jeremy Y. Ng

Peer Reviewers: Sera Whitelaw, Jennifer Williams

Article Dates: Received Nov 30 20; Accepted Feb 06 21; Published Apr 0221

\section{Citation}

Please cite this article as follows:

Musa E, Levitan AZ, Hughes G. Wearable health technology for the diagnosis and management of atrial fibrillation: A systematic review. URNCST Journal. 2021 Apr 02: 5(4). https://urncst.com/index.php/urncst/article/view/230

DOI Link: https://doi.org/10.26685/urncst.230

\section{Copyright}

(C) Ervis Musa, Adam Z. Levitan, Gavin Hughes. (2021). Published first in the Undergraduate Research in Natural and Clinical Science and Technology (URNCST) Journal. This is an open access article distributed under the terms of the Creative Commons Attribution License (https://creativecommons.org/licenses/by/4.0/), which permits unrestricted use, distribution, and reproduction in any medium, provided the original work, first published in the Undergraduate Research in Natural and Clinical Science and Technology (URNCST) Journal, is properly cited. The complete bibliographic information, a link to the original publication on http://www.urncst.com, as well as this copyright and license information must be included.

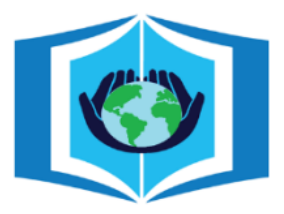

\section{URNCST Journal \\ "Research in Earnest"}

\section{Funded by the Government of Canada}

\section{Canadà̀}

Do you research in earnest? Submit your next undergraduate research article to the URNCST Journal!

| Open Access | Peer-Reviewed | Rapid Turnaround Time | International |

| Broad and Multidisciplinary | Indexed | Innovative | Social Media Promoted |

Pre-submission inquiries? Send us an email at info@urncst.com | Facebook, Twitter and LinkedIn: @URNCST

Submit YOUR manuscript today at https://www.urncst.com! 